\title{
Electrodeposition of Uranium and Thorium onto Small Platinum Electrodes
}

1 Michael A. Reichenberger ${ }^{1} *$, Takashi Ito ${ }^{2}$, Philip B. Ugorowski ${ }^{1}$, Benjamin W. Montag ${ }^{1}$, Sarah

${ }^{1}$ S.M.A.R.T. Laboratory, Mechanical and Nuclear Engineering Dept., Kansas State University, R. Stevenson ${ }^{1}$, Daniel M. Nichols ${ }^{1}$, Douglas S. McGregor ${ }^{1}$

$5 \quad{ }^{2}$ Department of Chemistry, Kansas State University, 213 CBC Building, Manhattan, KS 665060401, USA

Corresponding Author Email: mar89@ksu.edu

9 Preparation of thin U- and Th-coated $0.3 \mathrm{~mm}$ diameter Pt working electrodes by the cyclic

10 potential sweep method is described. Uranyl- and thorium hydroxide layers were

11 electrodeposited from ethanol solutions containing $0.02 \mathrm{M}$ natural uranyl and $0.02 \mathrm{M}$ natural

12 thorium nitrate, each with $3.6 \mathrm{M}$ ammonium nitrate. The cell for electrodeposition was specially

13 developed in order to accommodate the small working electrodes for this research by including a

14 working electrode probe, 3-D translation stage, and microscope. The source material deposition

15 was analyzed using digital microscopy and scanning electron microscopy, and confirmed using

16 x-ray fluorescence measurements. The appropriate potential range for electrodeposition was

17 determined to be $-0.62 \mathrm{~V}$ to $-0.64 \mathrm{~V}$ for a $0.3 \mathrm{~mm}$ diameter Pt working electrode placed $1 \mathrm{~cm}$

18 from the counter electrode. Smooth, uniform deposition was observed near the central region of

19 the working electrode, while surface cracking and crystalline formations were found near the

20 edge of the working electrode. The final procedure for sample substrate preparation, electrolytic

21 solution preparation and electrodeposition are described.

(C) 2015. This manuscript version is made available under the Elsevier user license http://www.elsevier.com/open-access/userlicense/1.0/ 


\section{Research Motivation}

2 The accurate deposition of thin $U$ and Th layers onto small metal electrodes is essential for the

3 continued development of Micro-Pocket Fission Detectors (MPFDs) [1]. MPFDs are under

4 development, which are constructed of materials resistant to the high-neutron flux and high-

5 temperature environment present in the core of many research nuclear reactors. Specifically,

6 MPFDs do not significantly perturb the local neutron flux, while providing a real-time

7 measurement of critical reactor parameters, and are capable of continuous operation during

8 extended testing periods. The small size, low sensitivity, and desired lifetime of MPFDs

9 necessitates a reliable method of electrodeposition of very thin layers of neutron-sensitive

10 materials onto radiation-hard substrate materials [1, 2]. Typical MPFDs require deposition

11 thicknesses of $350 \mu \mathrm{g} \cdot \mathrm{cm}^{-2}$ onto substrates $<1.0 \mathrm{~mm}^{2}$. The effectiveness of electrodeposition of

$12 \mathrm{U}$ and Th onto $0.3 \mathrm{~mm}$ diameter evaporated platinum electrodes on silicon substrates was

13 analyzed. Although MPFDs are typically constructed with alumina substrates, silicon substrates

14 were examined in this study for their ease in manufacturing and smooth surface finish. The

15 plating cell was developed in order to facilitate samples of substrate and electrode dimensions as

16 described. Natural $U$ and Th are desired for current MPFD fabrication [2]. Uranium and thorium

17 salts were used as source material for the electrolytic solutions.

18 Typical methods of surface deposition of $U$ and Th compounds include vacuum evaporation,

19 electro-spraying, painting with an organic solution, electrodeposition, and direct drop

20 precipitation [3]. Electrodeposition methods are commonly used to prepare actinide layers onto

21 targets for use as alpha particle sources and ion beam targets [3-5]. The use of nitrate-rich

22 solutions with organic solvents (isopropyl alcohol [4] and acetone [3]) has been reported for

23 electrodeposition preparation of target materials. Electrodeposition from organic solutions 
1 offered a very uniform layer, but often suffered from poor reproducibility [5]. Electrodeposition

2 methods are commonly optimized from the viewpoint of the maximum efficiency of the

3 electrodeposition, but depend heavily on electrochemical cell design [4, 5]. Still other methods

4 have been developed for rapid preparation of source material for nuclear waste analysis [3]. Both

5 of the previous methods call for working electrodes on the order of several square centimeters.

6 However, the objective of the present work is to deposit precise amounts of $U$ and Th on very

7 small electrodes $\left(<1 \mathrm{~mm}^{2}\right)$ for use as MPFD substrates. Although much of the chemistry from

8 previous methods can be used to aid in the development of MPFD substrates, the

9 electrodeposition method is being applied with a different objective. In contrast to many other

10 methods which strive for high electrodeposition efficiency, high precision and reproducibility is

11 important for the development and testing of MPFDs. The neutron-reactive coating for MPFDs

12 must be precisely deposited in order properly balance $\mathrm{U}$ and Th content to maximize device

13 lifetime [6].

14 Here, uranyl and thorium hydroxide layers were electrodeposited onto small Pt disk electrodes

15 using the cyclic potential sweep method [7]. The hydroxide layers were deposited by taking

16 advantage of an increase in $\mathrm{pH}$ at the vicinity of the electrodes as a result of the reduction of

17 nitrate [8]. The cyclic potential sweep method provides a more controlled means for such

18 electrochemically assisted deposition as compared to the more commonly used potential-step

19 method for the following two reasons. First, this method facilitates applying a potential required

20 for nitrate reduction for the shorter period of time by adjusting potential sweep rate. The longer

21 application of the cathodic potential using the potential-step method generates large gas bubbles

22 on the electrodes due to side reactions such as the reduction of water, preventing the deposition

23 of uniform hydroxide layers. The cyclic potential sweep permits the repetitive application of the 
1 cathodic potential for the shorter period of time to induce a sufficient $\mathrm{pH}$ increase with minimum

2 formation of large gas bubbles. Second, the deposition of the hydroxide layers can be monitored

3 from the cathodic current recorded during the repetitive potential sweep. The deposition of

4 insulating hydroxide layers leads to a decrease in the cathodic current due to the reduced

5 exposure of the active Pt electrode area. After determining the appropriate potential sweep range,

6 the number of potential segments can be adjusted to deposit a precise amount of $\mathrm{U}$ or Th material

7 onto the Pt electrode. The present work developed an electrochemical cell appropriate for work

8 with very small working electrodes and determined the effectiveness of the cyclic potential

9 sweep method for the fabrication of MPFD substrate materials.

\section{Experimental Method}

11 The production of sample MPFD substrates with thin $U$ and Th coatings consisted of three

12 primary steps: electrode fabrication, solution preparation, and electrodeposition.

\section{$13 \quad 2.1$ Electrode Fabrication}

14 Electron beam evaporation was used to deposit metal contacts onto insulating substrates for

15 electrodeposition testing. Shadow masks were used to create samples with circular electrodes as

16 depicted in Fig. 1. Custom nickel shadow masks were manufactured at the Kansas State

17 University Multiphase Microfluidics Laboratory using a Minitech Mini-Mill 3 micro-milling

18 machine. The present work used $0.3 \mathrm{~mm}$ diameter, circular electrodes evaporated onto silicon

19 dioxide substrates. Silicon dioxide was chosen for its smooth surface and ease in processing 20 post-evaporation.

21 Prior to evaporation, each 3-inch silicon wafer was cleaned using a 5-minute bath in each of 22 acetone and isopropyl alcohol, followed by a 1-minute buffered oxide etch and 5-minute de- 
1 ionized water bath. The wafer was then dried using pressurized nitrogen gas. The custom shadow

2 mask was fixed to the surface of silicon wafer just before insertion into the evaporation chamber.

3 A $50 \AA$ Ti evaporation was used to aid in the adhesion of the Pt layer. Afterwards, a $500 \AA \mathrm{Pt}$

4 layer was evaporated as the primary electrode material. Platinum was used due to its high

5 melting point, resistance to corrosion, and low neutron-absorption cross-section [9]. Samples

6 which did not utilize a thin Ti adhesion layer suffered from complete electrode material loss

7 during the wafer dicing process. Wafer processing and evaporation was conducted in the class-

8100 cleanroom facility at the Kansas State University S.M.A.R.T. Laboratory. Following

9 electrode evaporation, the wafers were diced into $5 \mathrm{~mm} \times 5 \mathrm{~mm}$ square samples for

10 electrodeposition testing. The samples were visually inspected for surface quality using a Hitachi

11 S-3400N scanning electron microscope, as depicted in Fig. 1.

12 FIGURE 1 HERE

\section{2.2 Solution Preparation}

14 Uranyl nitrate hexahydrate (99.9\%) and thorium nitrate hydrate $(99.8 \%)$ were used as the

15 respective sources of $U$ and $T h$ for each electrodeposition. The composition of the solutions used

16 for $\mathrm{U}$ and Th deposition differed only in the quantities of uranyl nitrate and thorium nitrate. Prior

17 to solution preparation, all of the glassware was cleaned using $\mathrm{HNO}_{3}$, acetone, isopropyl alcohol,

18 and a de-ionized water bath. The U/Th nitrate and ammonium nitrate were weighed using an

19 Ohaus AR0640 scale, combined into a $250 \mathrm{~mL}$ beaker, and de-ionized water was added to bring

20 the solution to $100 \mathrm{~mL}$. A $25 \mathrm{~mL}$ ethanol/de-ionized water solution was then prepared and added

21 to the U/Th nitrate and ammonium nitrate solution. The solution was placed on a magnetic

22 stirring plate on a low (3 of 10) stirring setting. The final solution was then topped off to $150 \mathrm{~mL}$

23 with de-ionized water and a $\mathrm{pH}$ measurement was taken using a calibrated Thermo Scientific 
1 Orion 3-Star $\mathrm{pH}$ monitor. The amount of each material used for the solution preparation and

2 measured $\mathrm{pH}$ are shown in Table 1. The U solution possessed a slight yellow tint, while the Th

3 solution was clear as depicted in Fig. 2. Precipitation of the U solution was observed after several

4 days. Thus, fresh electrolytic solution was prepared for each electrodeposition batch, and the

5 electrodeposition was conducted immediately after solution preparation.

6 TABLE 1 HERE

7 FIGURE 2 HERE

\section{$8 \quad 2.3$ Electrodeposition via the Cyclic Potential Sweep Method}

9 Samples were rinsed with isopropyl alcohol prior to electrodeposition. The $\mathrm{CH}$ Instruments

10 CHI600E potentiostat used for the present work utilized an electrochemical cell with three

11 electrodes. The electrochemical cell which was developed to accommodate the small electrode

12 design included a 3-dimensional translation stage, counter/reference electrode assembly, working

13 electrode probe, and Leica DMS300 microscope. The counter/reference electrode assembly was

14 constructed using an $\mathrm{Ag} / \mathrm{AgCl}$ reference electrode submerged in $3.0 \mathrm{M} \mathrm{KCl}$ inside a glass vial.

15 The counter electrode (0.013 inch diameter $99.95 \% \mathrm{Pt}$ wire) was then wrapped around the

16 reference electrode glass vial as shown in Fig. 3. The $5 \mathrm{~mm}$ x $5 \mathrm{~mm}$ silicon sample with

17 evaporated Pt working electrode and the counter electrode/reference electrode assembly were

18 placed into a glass petri dish. Electrolytic solution was added to submerge both the silicon

19 sample and the counter electrode. The stainless steel working electrode probe was insulated with

20 exception of the tip to enable electrical contact with the working electrode, visible in Fig. 4. The

21 3-D stage was then adjusted to establish contact between the Pt electrode on the silicon sample

22 and the working electrode probe, also depicted in Fig. 4. After electrical contact was established,

$23 \mathrm{U} / \mathrm{Th}$ was deposited onto the working electrode surface. 
FIGURE 3 HERE

2 FIGURE 4 HERE

3 Determination of the optimal parameters required numerous trials, however a potential sweep

4 from $-0.62 \mathrm{~V}$ to $-0.64 \mathrm{~V}$ was determined to yield the most consistent surface deposition using a

$5 \quad 0.01 \mathrm{Vs}^{-1}$ sweep rate. Voltages beyond $-0.64 \mathrm{~V}$ produced severe bubble generation and yielded

6 more unwanted crystalline deposits on the surface of the working electrode. Additionally, no

7 electrodeposition was observed from $0 \mathrm{~V}$ to $-0.62 \mathrm{~V}$. The present work tested the effectiveness of

8 electrodeposition with 500 potential sweep segments. The electrodeposition was performed at

9 room temperature (typically below $28{ }^{\circ} \mathrm{C}$ ). The cyclic potential sweep process yielded current-

10 voltage plots (cyclic voltammograms) representative of those depicted in Fig. 5 for uranyl-nitrate

11 and thorium-nitrate solutions. All samples were rinsed with isopropyl alcohol after

12 electrodeposition and allowed to dry before storage in individual sealed plastic bags.

13 FIGURE 5 HERE

16 During each potential sweep segment, a small amount of insulating U/Th hydroxide was

17 deposited onto the working electrode surface. As additional material was deposited, the 18 electrochemically active surface area of the working electrode decreased to give a smaller

19 cathodic current, as shown in Fig. 5. Small bubbles occasionally formed at the contact point of 20 the working electrode probe and working electrode surface but quickly detached. The deposited 21 material was clearly visible as the Pt surface changed in color from silver to yellow (U) and

22 white (Th). A plated Th sample just after electrodeposition is shown in Fig. 6. Digital 
1 microscopy, scanning electron microscopy (SEM), and x-ray fluorescence (XRF) analysis were

2 all used to determine the effectiveness of the electrodeposition process.

3 FIGURE 6 HERE

4 A Leica DVM 2500 microscope was used to visually inspect each sample. The color of the

5 samples indicated areas where U- or Th-hydroxides were deposited. Uranium samples had

6 golden-colored electrode surfaces while Th samples had white-colored electrode surfaces.

7 Special notes were taken of any regions where the electrode surface appeared absent of deposited

8 material. Some samples exhibited crystalline depositions around the perimeter of the electrode

9 surface as shown in Fig. 7.

10 FIGURE 7 HERE

11 The SEM was used to examine the surface features of the samples after electrodeposition, 12 showing three distinct regions depicted in Fig. 8. The first region was a smooth, conformally 13 coated region located in the center of the sample and extending radially as depicted in Fig. 8(A).

14 Near the edges of the samples, a cracked layer was observed, shown in Fig. 8(B). The crystalline

15 formations depicted in Fig. 7 were also observed in the same region as the surface cracking. The

16 crystalline depositions were observed to detach easily by coming in contact with the plastic

17 container in which the samples were stored. The cracked region was preferentially observed on

18 the side closest to the counter electrode. XRF analysis of the cracked region suggested larger

19 amount of U/Th in the cracked region. Finally, regions were observed on each sample where

20 little or no deposition had taken place shown in Fig. 8(C). These regions varied in size and shape

21 but are possibly due to surface contamination (dust particles for example), probe contact, or

22 detachment of a hydroxide layer.

23 FIGURE 8 HERE 
1 X-ray fluorescence measurements were used as a qualitative assessment of the amount of $\mathrm{U}$ or

2 Th deposited on each sample. Measurements were conducted for each of the regions of interest

3 for each sample. The relative abundance of each sample material was calculated based on the

4 XRF measurement results. Silicon, oxygen, and platinum were also included in the surface

5 composition estimate due to the penetrating ability of the SEM electron beam and subsequent

6 characteristic x-rays. Clear peaks were present in the XRF spectra depicted in Fig. 9 for U and

7 Th. Results of XRF analysis for each region for a characteristic sample are summarized in Table

8 2. The XRF results clearly indicate deposition of both $U$ and Th onto the electrode surface, but

9 also suggest that thicker deposition occurs near the perimeter of the working electrode.

10 FIGURE 9 HERE

11 FIGURE 11 HERE

12 TABLE 2 HERE

\section{Conclusions}

14 Uranium and thorium hydroxides were successfully deposited on $0.3 \mathrm{~mm}$ diameter circular $\mathrm{Pt}$

15 electrodes on a silicon dioxide substrate using the cyclic potential sweep method. Digital

16 microscopy, SEM, and XRF have all been used to analyze the surface of the Pt electrodes after

17 electrodeposition. The exact composition of the surface deposition is unknown at this time, but is

18 likely to be uranyl and thorium hydroxide considering the mechanism of the electrodeposition.

19 Crystalline formations of higher $\mathrm{U}$ and Th content were found near the perimeter of the electrode

20 surfaces, likely due to the higher electric field strength and enhanced diffusion of ions near the

21 edge of the metal electrode. This effect was observed to be even more prominent on the side of

22 the electrode which was closest to the counter electrode. The effectiveness of electrodeposition

23 will depend heavily upon the electrode size and shape. The central region of the Pt electrodes 
1 exhibited a conformal coating of U/Th compounds as verified by XRF analysis. Mass

2 measurements of $U$ and $T h$ coated samples are currently under investigation. The number of

3 sweep segments will also likely affect the amount of U/Th which is deposited on the working

4 electrode and is currently being characterized.

\section{Acknowledgements}

6 Portions of this work have been supported by the US Department of Energy Office of Nuclear

7 Energy under DOE-NE Idaho Operations Office Contract DE-AC07 05 ID14517 \& US

8 Department of Energy Office of Nuclear Energy under DE-NE0008305. The authors would like

9 to thank Dr. Amy Betz and the Kansas State University Multiphase Microfluidics Laboratory for

10 use of equipment and assistance in machining shadow masks for this work.

\section{References}

[1] T. Unruh, J. Daw, K. Davis, D. Knudson, J. Rempe, M. Reichenberger, P. Ugorowski, D. McGregor, J. F. Villard, "Enhanced Micro Pocket Fission Detector Evaluations," in NPIC \& HMIT, Charlotte, NC, 2015.

[2] T. Unruh, J. Rempe, D. S. McGregor, P. B. Ugorowski, M. A. Reichenberger, "NEET MicroPocket Fission Detector - FY 2013 Status Report.," Idaho National Laboratory (INL), Idaho Falls, 2013.

[3] L.C. Hao, C.V. Tao, N.V. Dong, H.N. Nghi, P.T. Dung, L.V. Thong, "Rapid Preparationof Uranium and Thorium Aplpha Sources by Electroplating Technique," Kerntechnik, vol. 75, no. 6, pp. $381-385,2010$. 
[4] R.A. Henderson, J.M. Gostic, J.T. Burke, S.E. Fisher, C.Y. Wu, "Electrodeposition of U and $\mathrm{Pu}$ on thin $\mathrm{C}$ and Ti substrates," Nuclear Instruments and Methods in Physics Research A, vol. 655, pp. 66 - 71, 2011.

[5] C. Ingelbrect, A. Moens, R. Eykens, A. Dean, "Improved Electrodeposited Actinide Layers," Nuclear Instruments and Methods in Physics Rsearch A, vol. 397, pp. 34-38, 1997.

[6] M. A. Reichenberger, P. B. Ugorowski, J. A. Roberts, D. S. McGregor, "First-Order Numerical Optimization of Fission-Chamber Coatings Using Natural Uranium and Thorium," in Proc. IEEE Nuc. Sci. Symp., Seattle, WA, 2014.

[7] K. Hosokawa, M. Matsunaga, Y. Tsuru, N. Uemura, "Study of Ruthenium Electrodeposition by Cyclic Potential Sweep Method," Denki Kagaku, vol. 53, no. 2, pp. 153-153, 1985.

[8] N. I. Kovtyukhova, T. E. Mallouk, "Electrochemically Assisted Deposition as a New Route to Tranparent Coductive Indium Tin Oxide Films," Chemistry of Mat., no. 22, pp. 4939-4949, 2010.

[9] National Nuclear Data Center, "Evaluated Nuclear Data File (ENDF)," Brookhaven National Laboratory, 2014.

\section{Tables \& Figures}

4 Table 1 Compositions of solutions used for electrodeposition of uranyl and thorium hydroxide 5 layer on Pt electrodes.

7 Table 2 XRF results representing the relative abundance of four elements on U-deposited and 8 Th- deposited Pt electrodes $(\sim 150 \mu \mathrm{m} \times 150 \mu \mathrm{m}$ for each region). 
2 Fig. 1. SEM image of a circular Pt electrode prior to electrodeposition. The size and shape of 3 each sample was verified after evaporation.

4

5 Fig. 2. Prepared solutions of $0.02 \mathrm{M} \mathrm{UO}_{2}\left(\mathrm{NO}_{3}\right)_{2}$ (left) and $0.02 \mathrm{M} \mathrm{Th}\left(\mathrm{NO}_{3}\right)_{4}$ (right).

6

7 Fig. 3. Schematic illustration of the electrochemical cell consisting of a reference electrode, 8 count electrode, and working electrode.

10 Fig. 4. An optical microscope image of a Pt electrode with the working electrode probe prior to 11 electrodeposition. Proper alignment of the working electrode probe and Pt electrode was 12 necessary before electrodeposition was possible.

14 Fig. 5. Current vs potential plots measured at the sweep rate of 0.01 Vs-1 in (A) $0.02 \mathrm{M}$ $15 \mathrm{UO}_{2}\left(\mathrm{NO}_{3}\right)_{2}$ and $(\mathrm{B}) 0.02 \mathrm{M} \mathrm{Th}\left(\mathrm{NO}_{3}\right)_{4}$. The cathodic current gradually decreased as a result of 16 the repetitive potential sweep due to the deposition of a $(\mathrm{A}) \mathrm{UO}_{2}(\mathrm{OH})_{2}(\mathrm{~A})$ and $(\mathrm{B}) \mathrm{Th}(\mathrm{OH})_{4}$ 17 layer on the Pt electrode surface.

19 Fig. 6. Optical microscopy image of a Pt electrode after electrodeposition of the Th hydroxide.

20 The electrode surface slowly changed color during the electrodeposition from silver (Pt) to white 21 (Th). 
1 Fig. 7. Optical microscopy image of a Pt electrode after U electrodeposition. Surface cracking

2 and crystalline formation is visible near the perimeter of the electrode.

4 Fig. 8 SEM image of a U-deposited Pt electrode showing three distinct regions: (A) a uniformly 5 deposited region, (B) a region with thick deposition layers, and (C) an undeposited region.

7 Fig. 9. XRF spectrum measured at the surface of a (A) U- and (B) Th-deposited Pt electrode.

8 Numerous $\mathrm{U}$ characteristic $\mathrm{x}$-ray peaks were clearly present. Peaks for $\mathrm{Pt}, \mathrm{Si}$, and $\mathrm{O}$ are also

9 present due to the penetration of $x$-rays from the substrate through the thin electrodeposited 10 layer. 


\section{$13.4 \mu \mathrm{m}$}

1

$493 \mu \mathrm{m}$

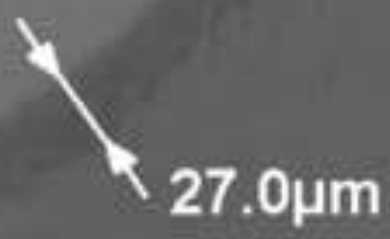

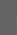

I 1

1

I 
Electrode

Working Electrode Probe

\section{Counter}

.

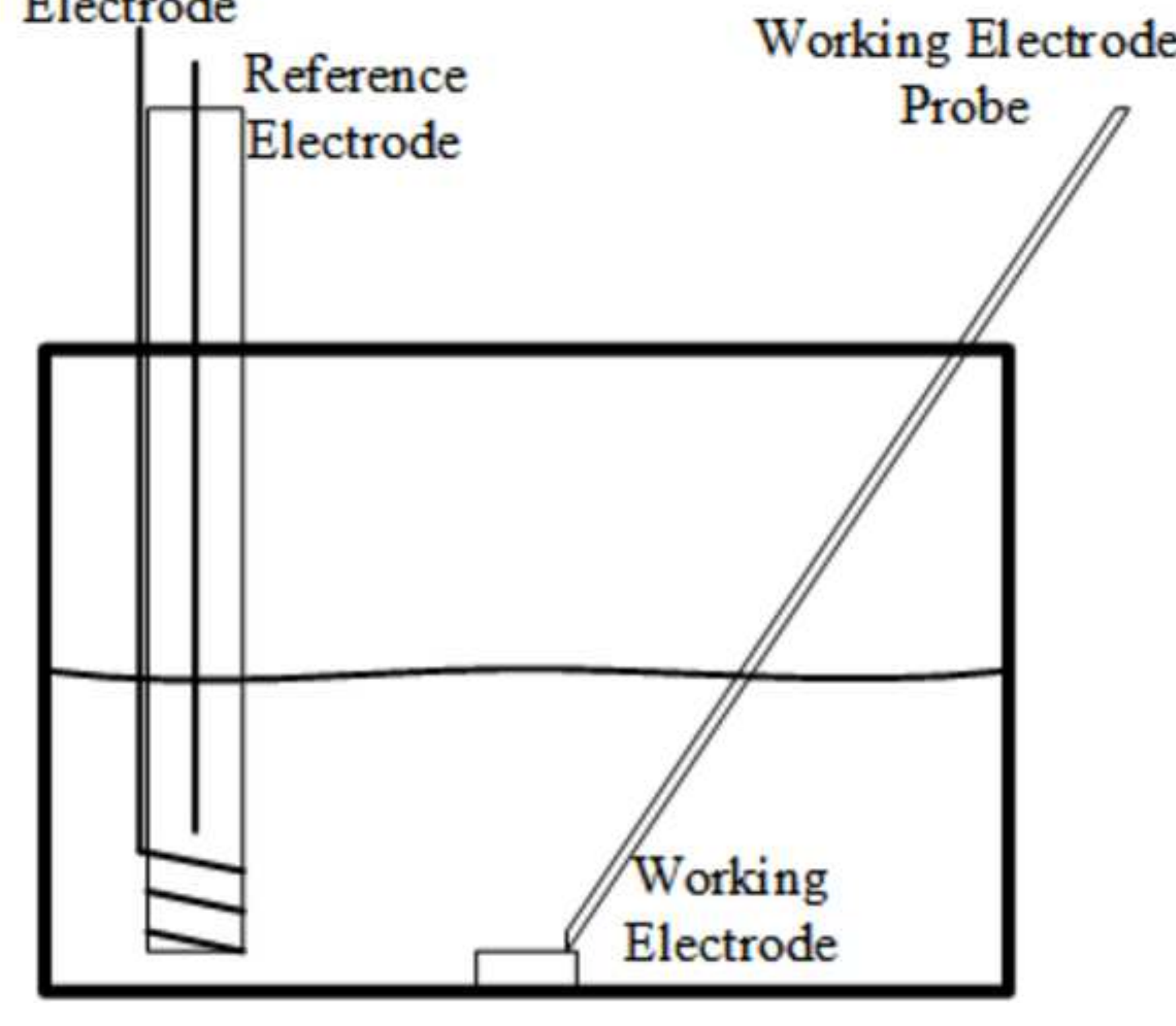




\section{Figure}

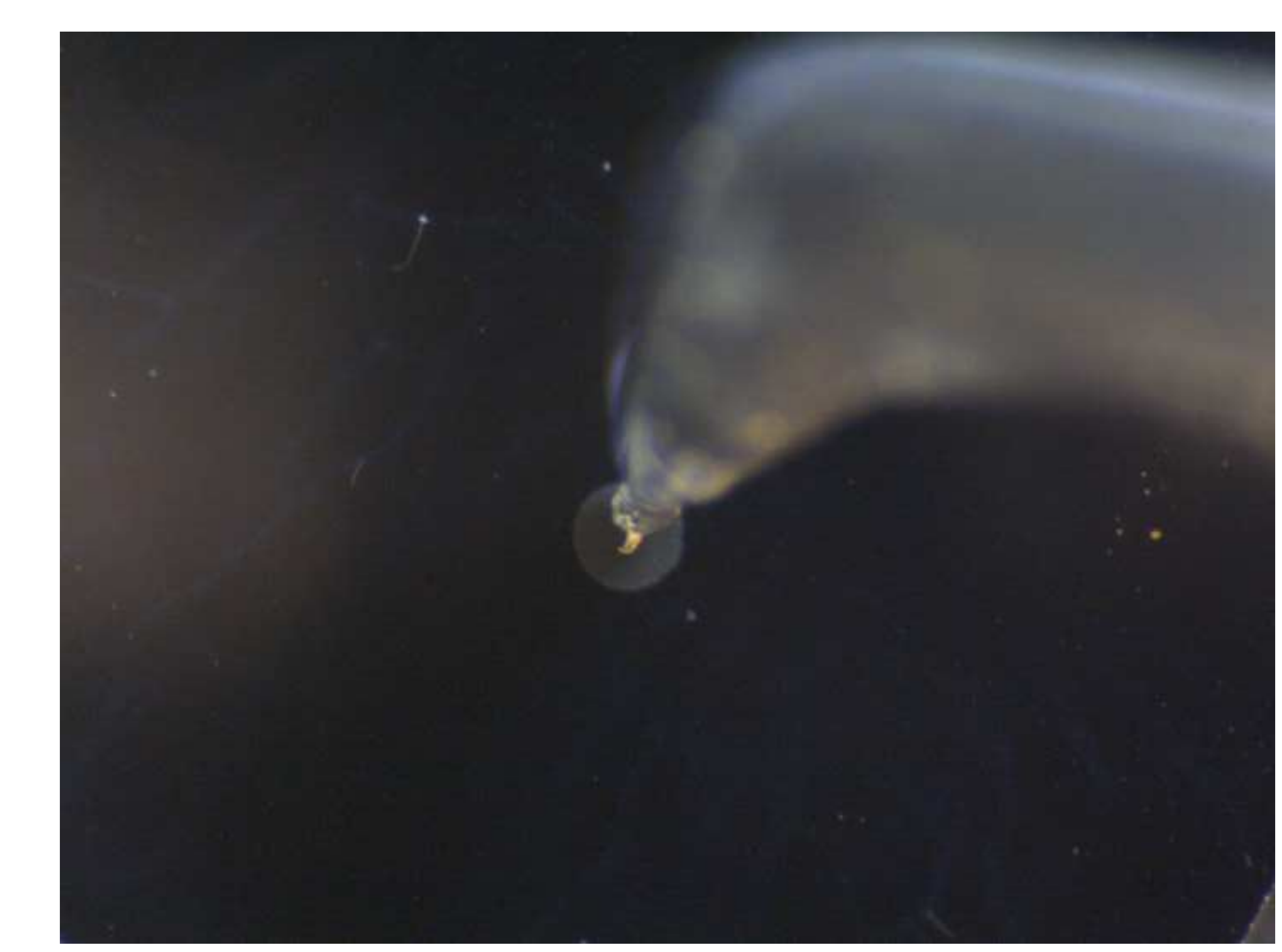




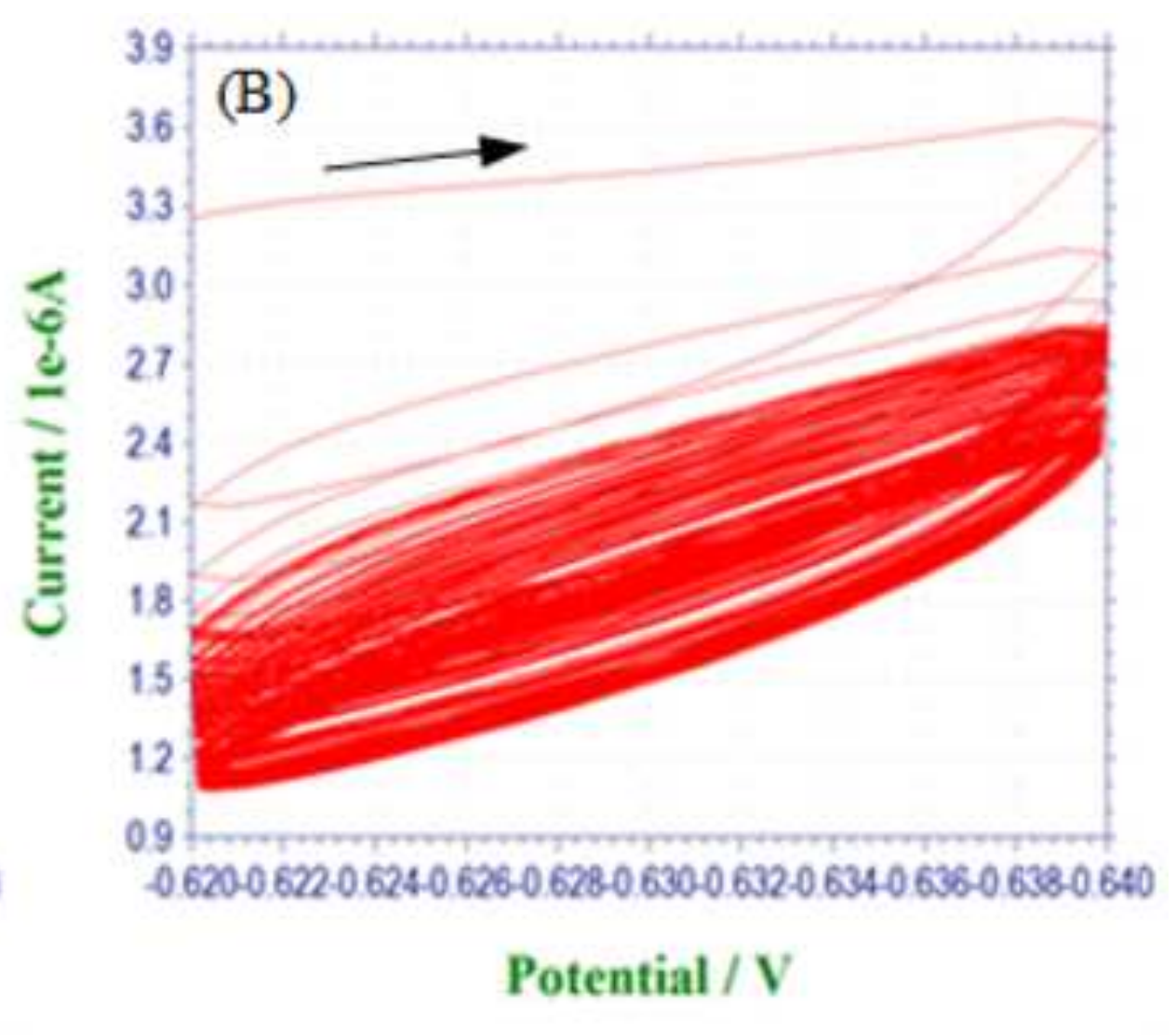

Potential / V

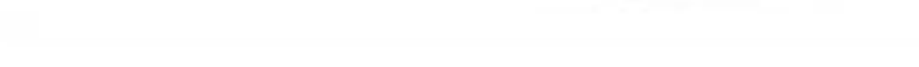

.

Potential / V

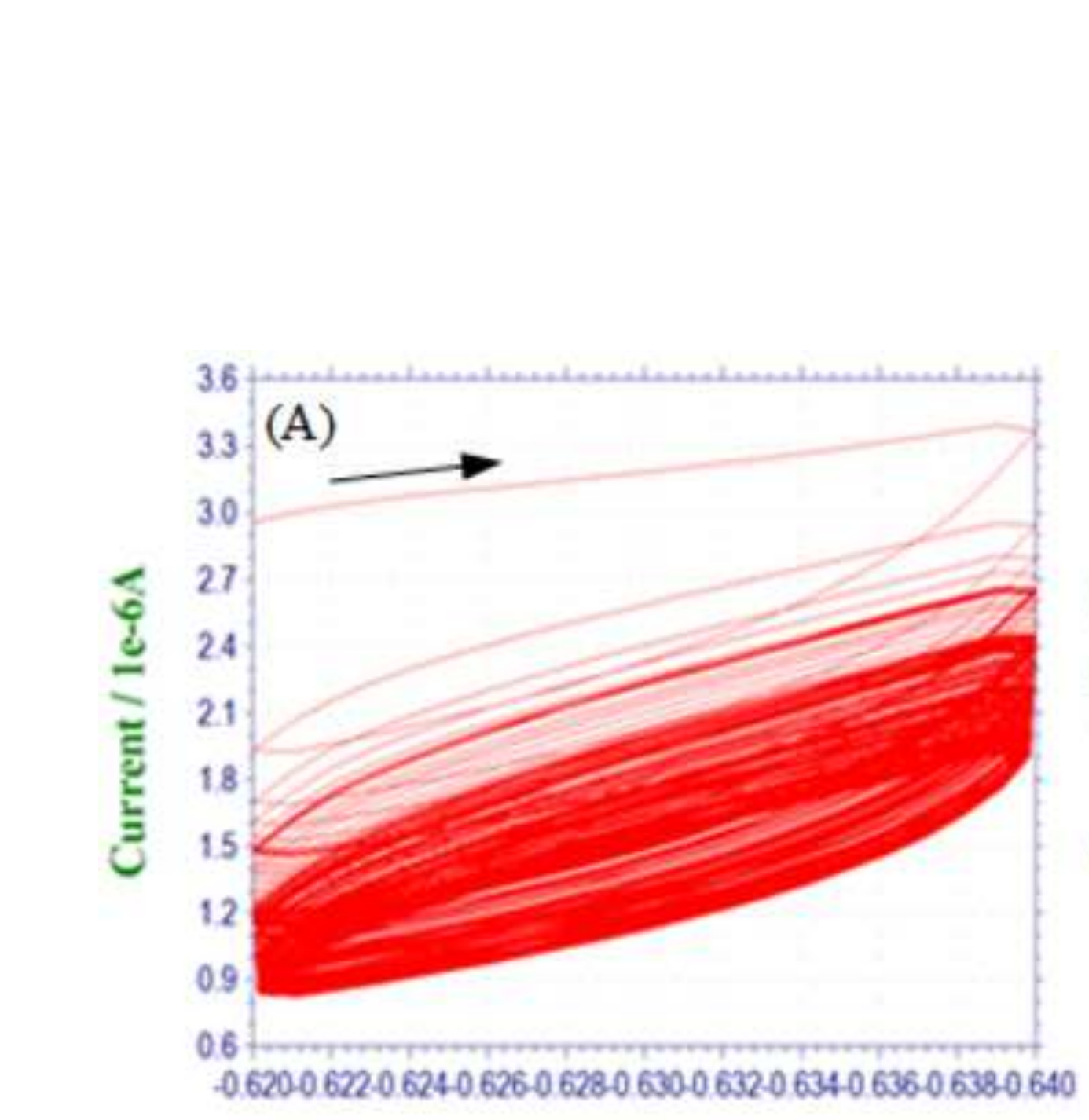

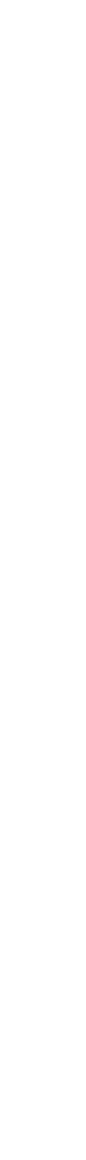
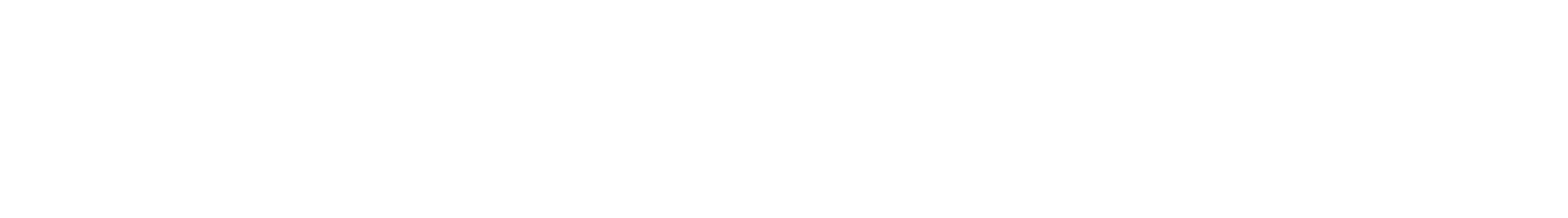


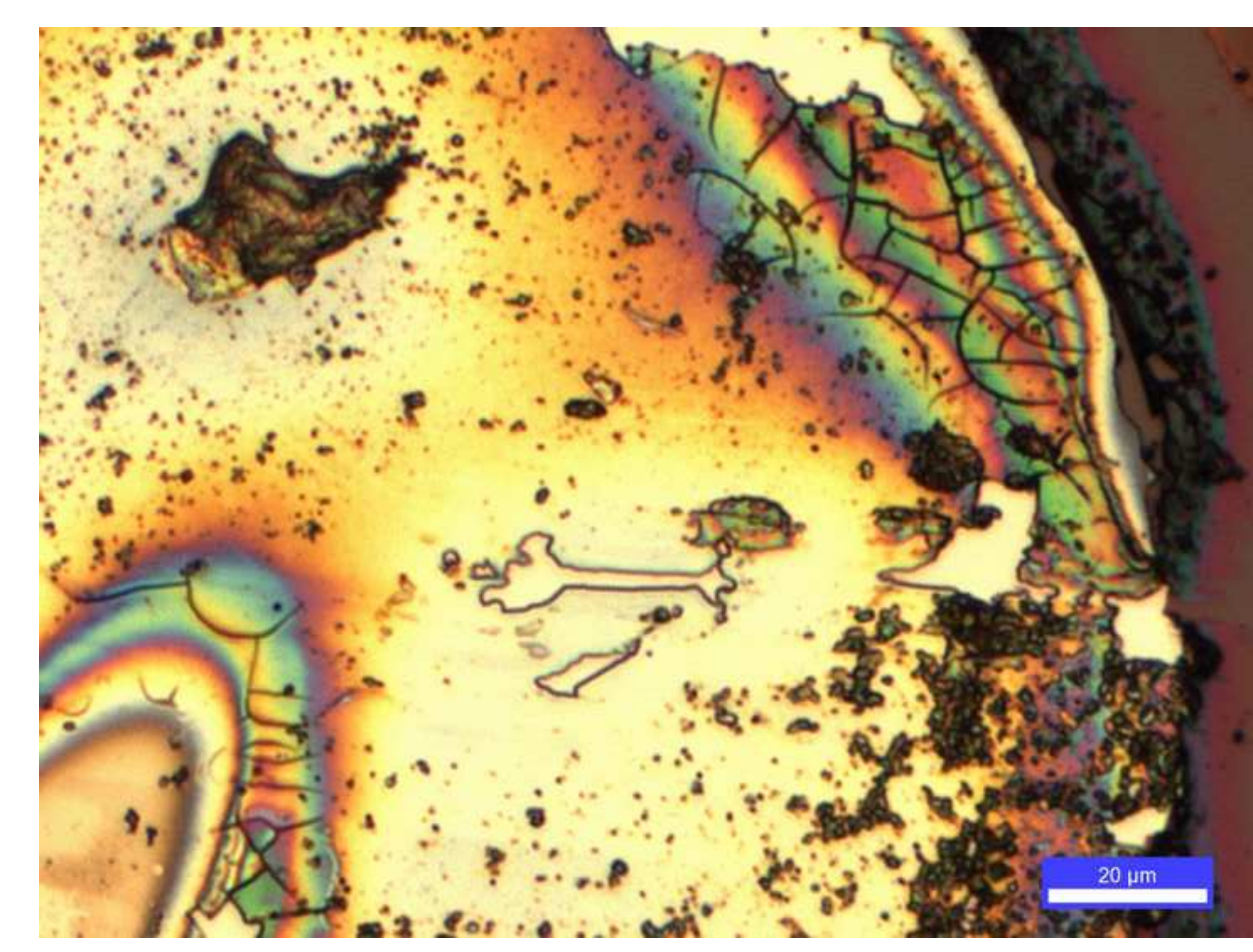

3

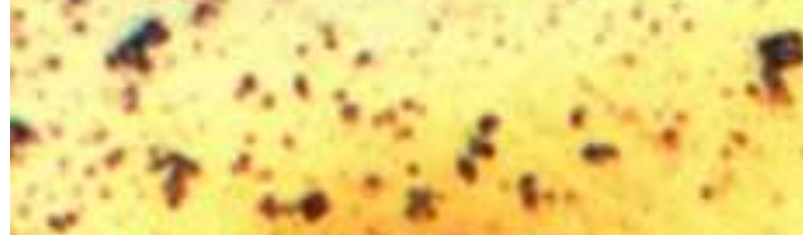

I. e.

$\sum_{i=1}^{*}$

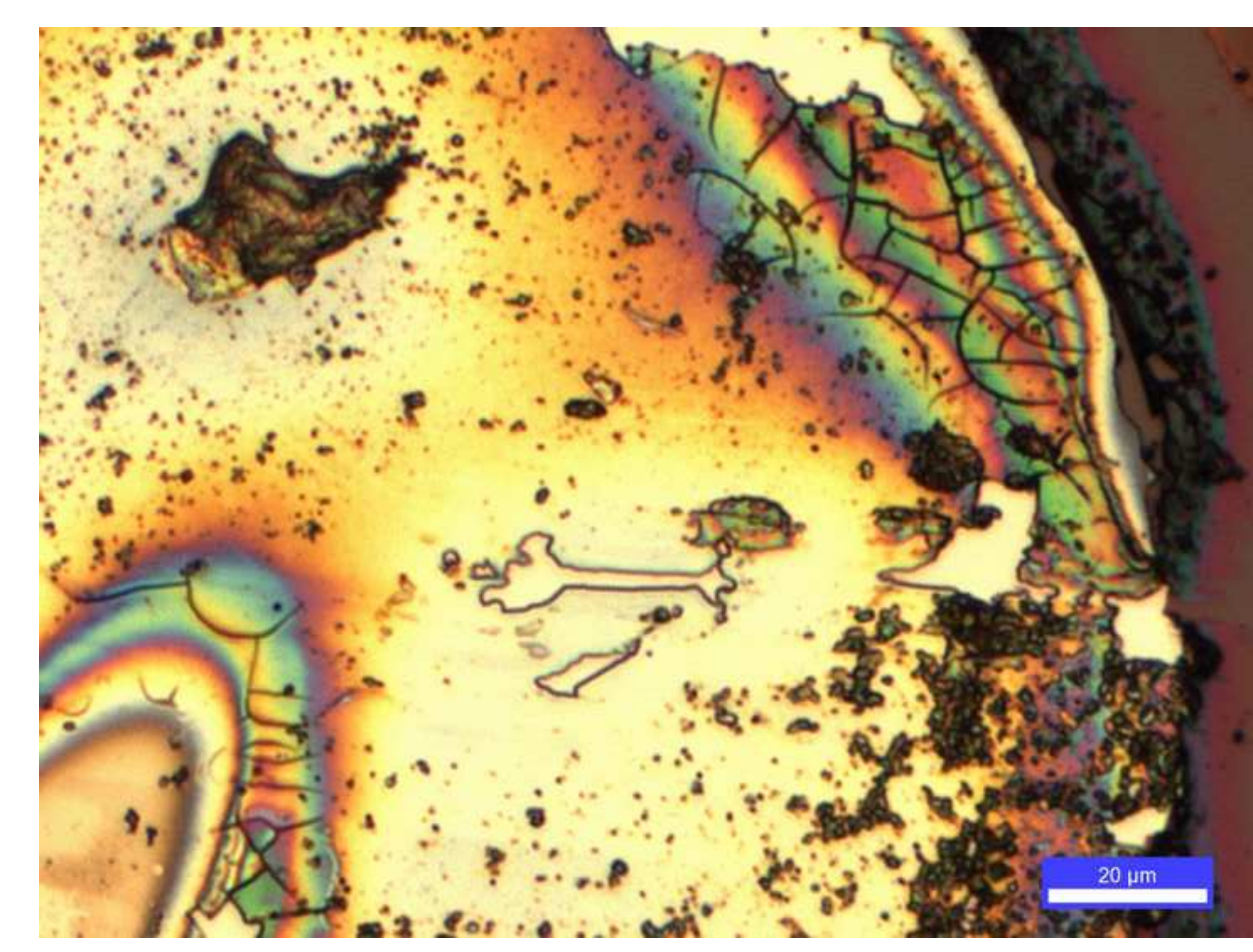

i ax 10 $+4$

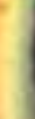

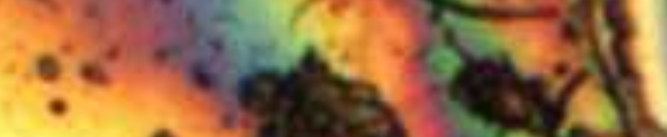

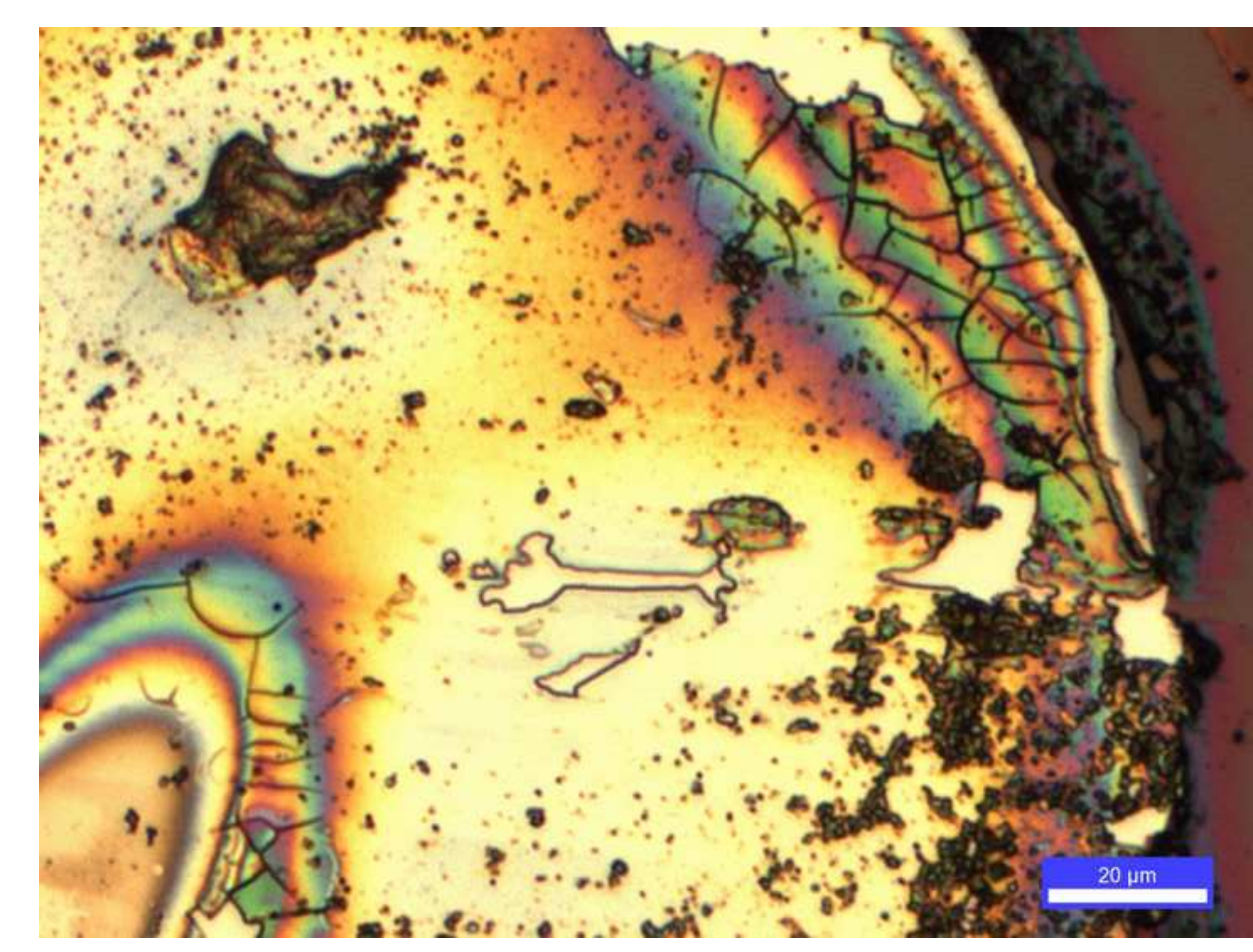
$\therefore \quad \pi$

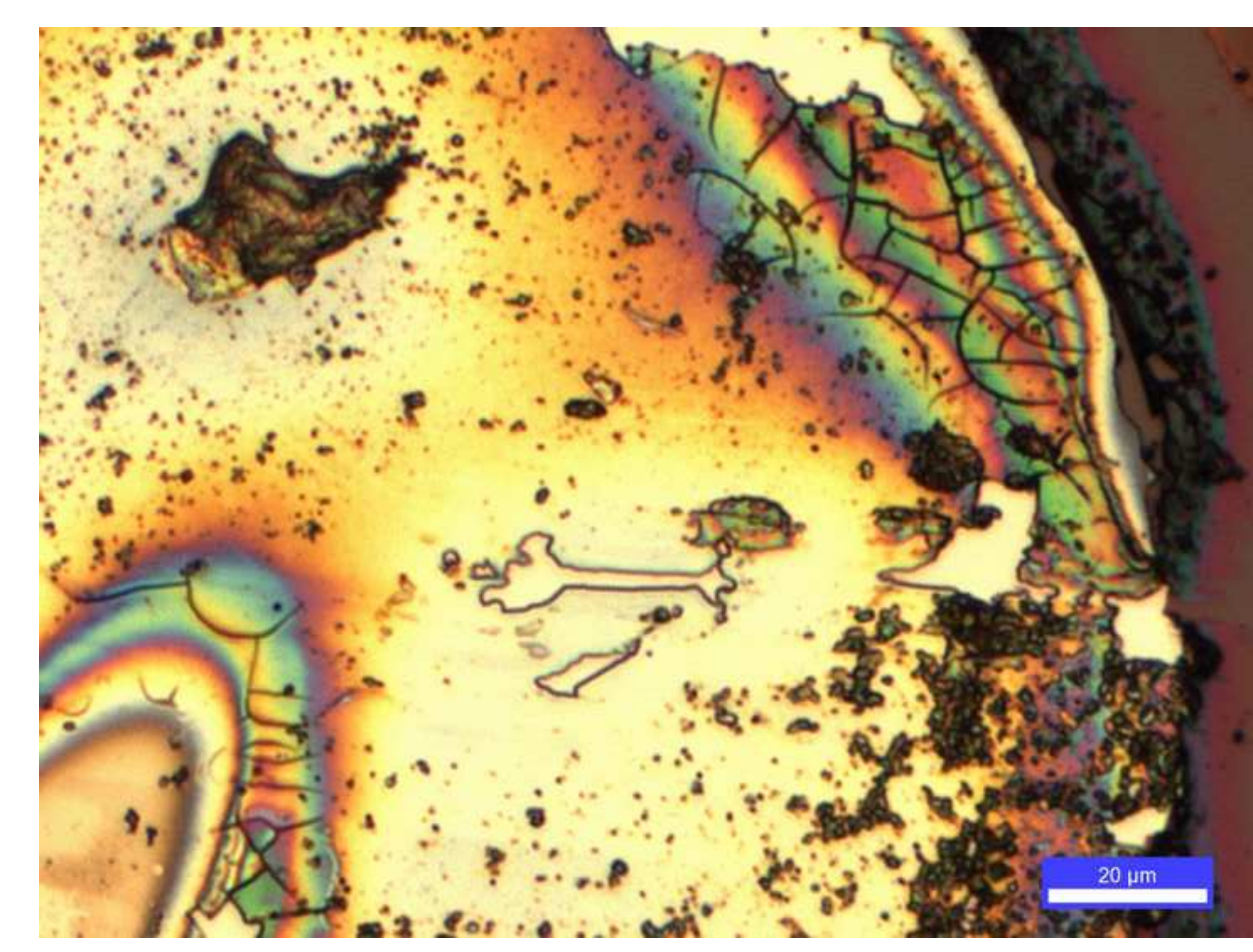

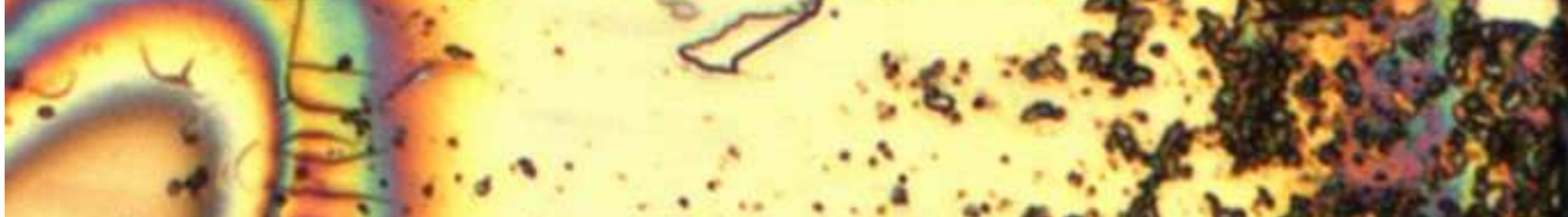

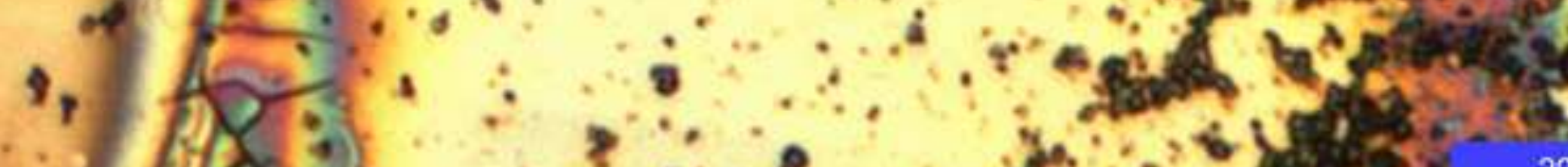

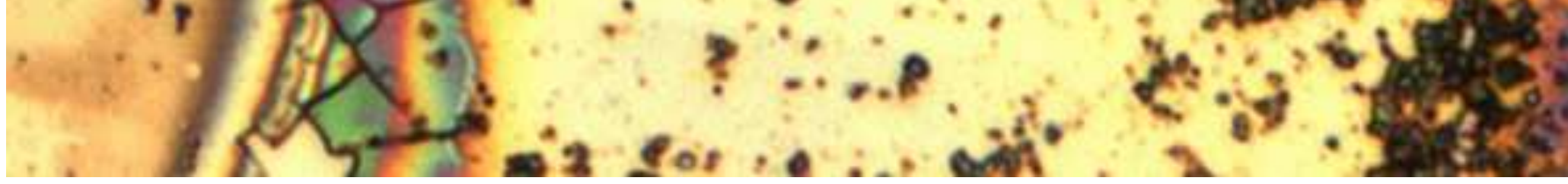
s. $20 \mu \mathrm{m}$ ... $\mathrm{N}$ स

$$
\text { ( }
$$$$
\text { ( }
$$ 


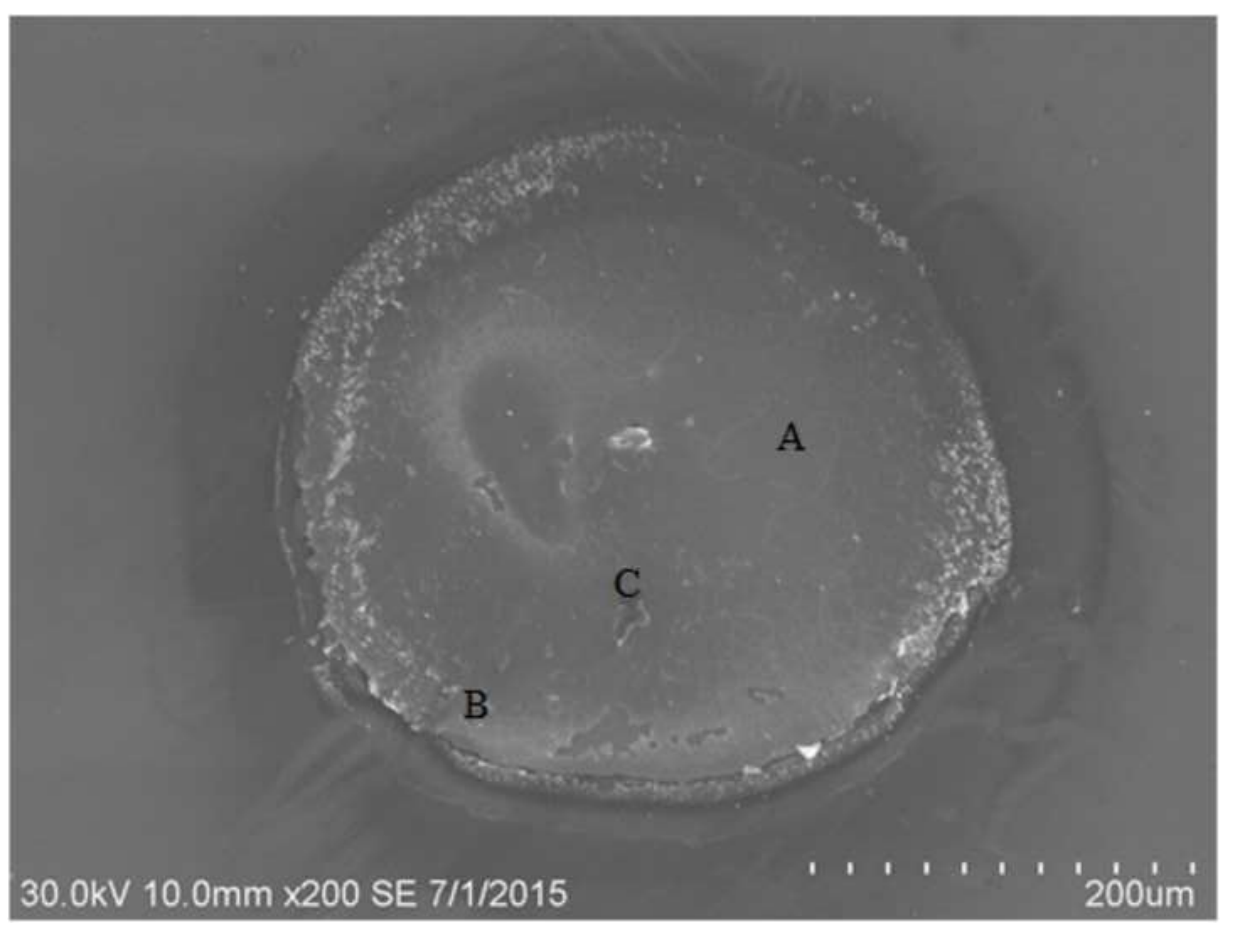

30.0kV $10.0 \mathrm{~mm} \times 200$ SE $7 / 1 / 2015$

\section{Figure8 \\ Figure}
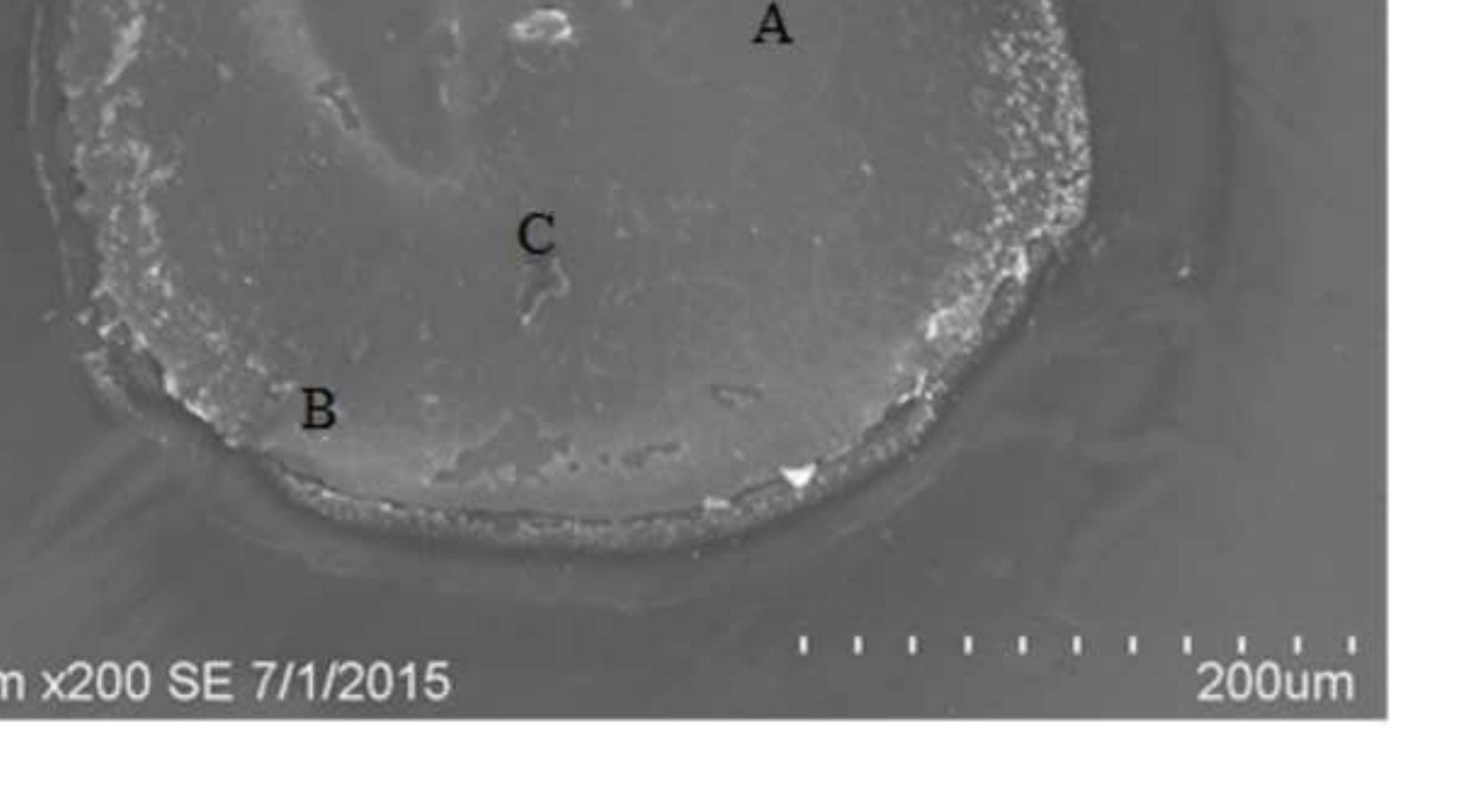

.
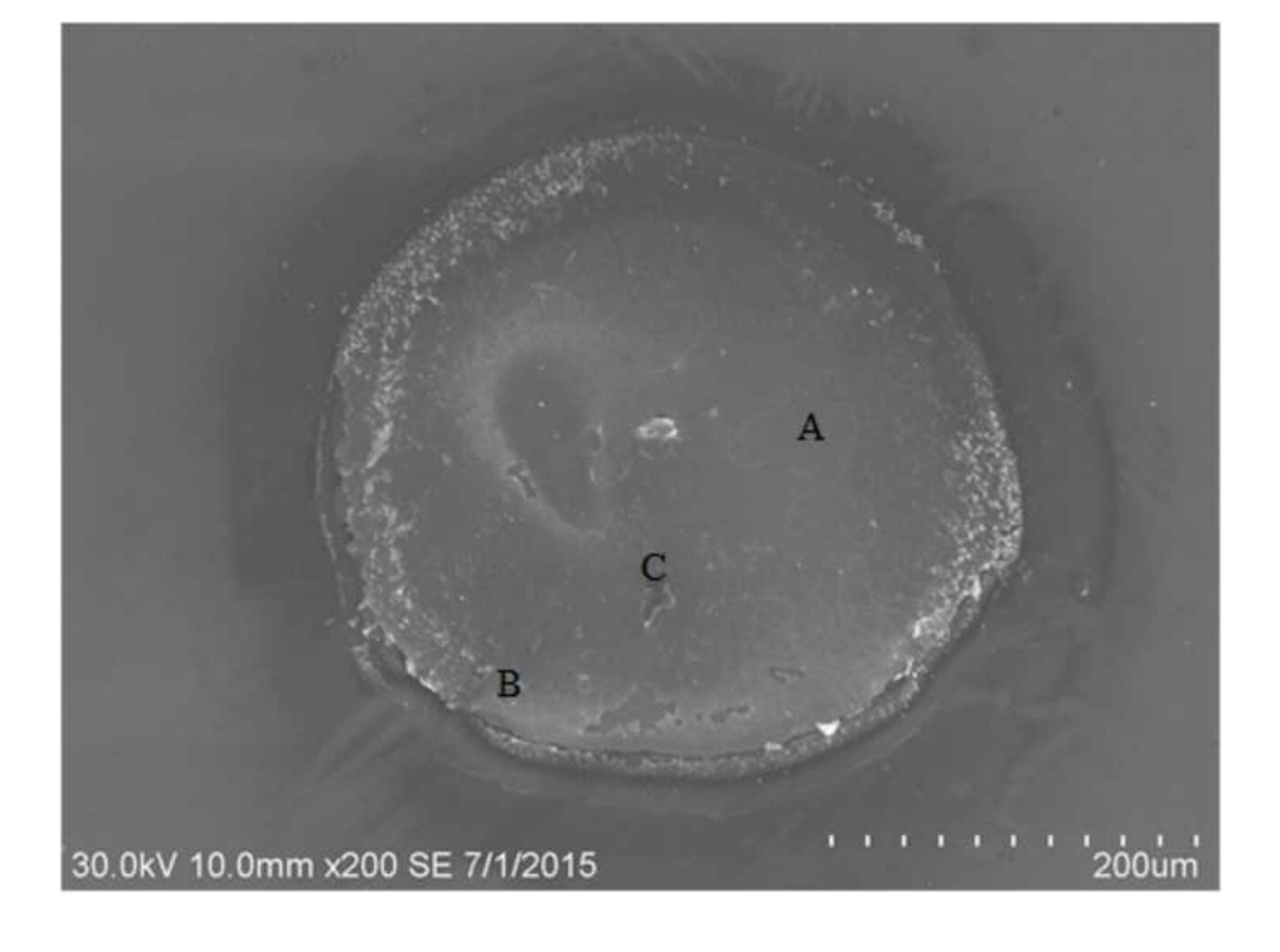

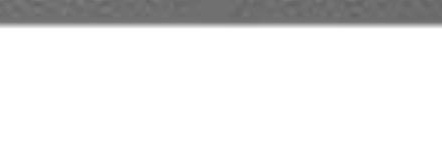
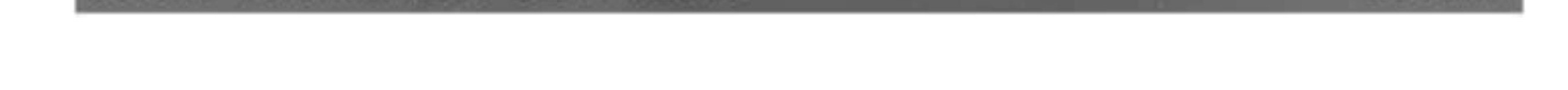


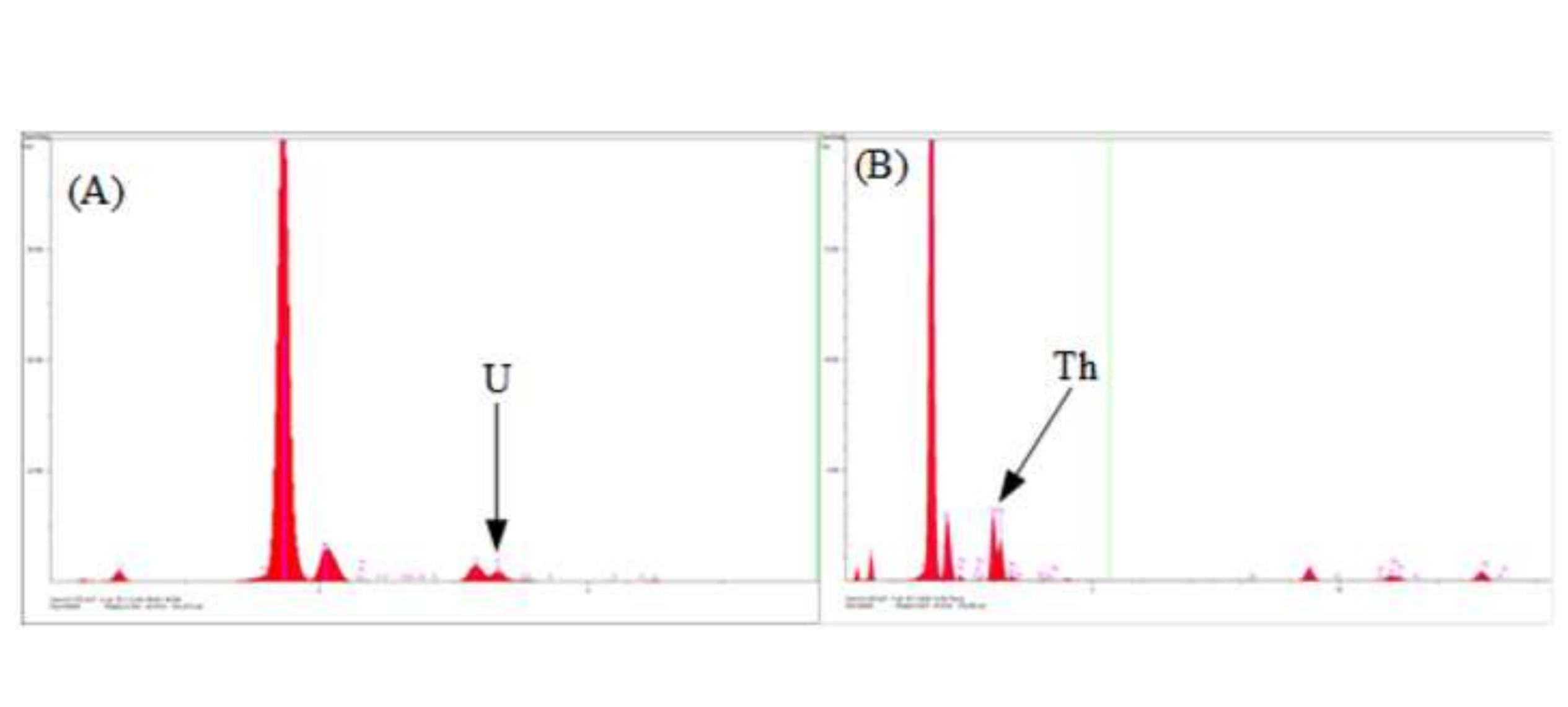

.

.
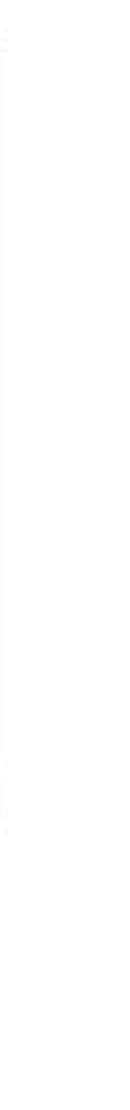


\begin{tabular}{|l|r|r|r|c|}
\hline $\begin{array}{l}\text { Compon } \\
\text { ent }\end{array}$ & \multicolumn{2}{|c|}{$\mathbf{0 . 0 2} \mathrm{M} \mathrm{UO}_{\mathbf{2}}\left(\mathrm{NO}_{\mathbf{3}}\right)_{\mathbf{2}}$} & \multicolumn{2}{|l|}{$\mathbf{0 . 0 2} \mathrm{M} \mathrm{Th}\left(\mathrm{NO}_{\mathbf{3}}\right)_{\mathbf{4}}$} \\
\hline $\begin{array}{l}\text { Uranyl } \\
\text { or } \\
\text { Thorium } \\
\text { Nitrate }\end{array}$ & 410 & $\mathrm{mg}$ & 480 & $\mathrm{mg}$ \\
\hline $\begin{array}{l}\text { Ammoni } \\
\text { um } \\
\text { Nitrate }\end{array}$ & 14,410 & $\mathrm{mg}$ & 14,410 & $\mathrm{mg}$ \\
\hline $\begin{array}{l}\mathbf{1 9 0} \\
\text { Proof } \\
\text { Ethanol }\end{array}$ & 5.78 & $\mathrm{~mL}$ & 5.78 & $\mathrm{~mL}$ \\
\hline $\begin{array}{l}\text { Measure } \\
\text { d } \\
\text { Solution } \\
\text { pH }\end{array}$ & 3.4 & & 3 & \\
\hline
\end{tabular}




\begin{tabular}{|c|c|c|c|c|}
\hline $\begin{array}{l}\text { Sample } \\
\text { and } \\
\text { Region }\end{array}$ & $\begin{array}{c}\text { Si } \\
\text { Concentra } \\
\text { tion }\end{array}$ & $\begin{array}{c}\text { Pt } \\
\text { Concentra } \\
\text { tion } \\
\end{array}$ & $\begin{array}{c}\text { O } \\
\text { Concentra } \\
\text { tion }\end{array}$ & $\begin{array}{c}\text { U / Th } \\
\text { Concentra } \\
\text { tion }\end{array}$ \\
\hline $\begin{array}{l}\text { U Central } \\
\text { Region }\end{array}$ & 64 wt. $\%$ & 6 wt. $\%$ & 21 wt. $\%$ & 9 wt. $\%$ \\
\hline $\begin{array}{l}\text { U Cracked } \\
\text { Region }\end{array}$ & $61 w t \%$ & 11 wt. $\%$ & 15 wt. $\%$ & 13 wt. $\%$ \\
\hline $\begin{array}{l}\text { Th Central } \\
\text { Region }\end{array}$ & 78 wt. $\%$ & 10 wt. $\%$ & 11 wt. $\%$ & 1 wt. $\%$ \\
\hline $\begin{array}{l}\text { Th } \\
\text { Cracked } \\
\text { Region } \\
\end{array}$ & 53 wt. $\%$ & 9 wt. $\%$ & 16 wt. $\%$ & 22 wt. $\%$ \\
\hline
\end{tabular}

